\title{
Fly ash application in moorum embankment and its stability analysis using FLAC/SLOPE and Response Surface Method
}

Sagar Dattatray Turkane ( $\square$ sagarturkane24@gmail.com )

National Institute of Technology Raipur https://orcid.org/0000-0001-9244-0246

Sandeep Kumar Chouksey

National Institute of Technology Raipur

\section{Research Article}

Keywords: Moorum, Fly ash, FLAC/slope, RSM, FOS.

Posted Date: June 17th, 2021

DOl: https://doi.org/10.21203/rs.3.rs-631949/v1

License: (c) (1) This work is licensed under a Creative Commons Attribution 4.0 International License.

Read Full License 


\section{Abstract}

This paper presents the application of fly ash in moorum embankment by partial replacement of moorum with fly ash and its stability analysis has been carried out. An experimental investigation was carried out on moorum blended with fly ash at different proportions of fly ash by dry weight of soil for the moorum embankment stability analysis. The Index properties and strength properties were assessed by performing Atterberg's limit, specific gravity, grain size distribution, compaction test, direct shear test (DST), and California Bearing Ratio (CBR) test respectively. The embankment slope stability analysis was performed using FLAC/SLOPE version 8.10 (Fast Lagrangian Analysis of Continua) software at a various slope angle of $30^{\circ}, 32^{\circ}$, and $34^{\circ}$ and different heights of the embankment of $6 \mathrm{~m}, 8 \mathrm{~m}$, and $10 \mathrm{~m}$ to calculate Factor of Safety (FOS). FOS decreases with the increment of fly ash content, the height of embankment, and slope angle respectively. In addition to the numerical analysis, Response Surface Methodology (RSM) based (Face-Centered Central Composite Design) was used to predict FOS. The developed mathematical equation illustrates that the RSM model was statistically significant and the results give a reliable prediction of FOS.

\section{Introduction}

Currently, India produces nearly about 169.25 (MMT) million metric tons of coal ash; by burning coal which is expected to be twice over in upcoming next 10 years (Bose 2012). Whereas the relative utilization is very less approximately $63.28 \%$ that is 107.10 million metric tons of fly ash as per report (Central Electricity Authority 2018). This unused ash has harmful effects on the natural world, urging the need to use fly ash properly or increase the rate of utilization of fly ash. In geotechnical construction activities such as embankments and filling materials etc., fly ash can effectively use as filler material. This is the most favorable solution to disposal issue of the fly ash and also to reduce the cost construction.

Whenever fly ash is used as a construction material its properties and strength/stability along with parent material need to be check before actual uses. Several extensive research has been investigated the effective utilization of low calcium-based soil stabilizers, such as fly ash for the improvement in the soil characteristics (Sivapullaiah et al. 1996; Cokca 2001; Kaniraj and Gayathri 2003; Phani Kumar and Sharma 2004; Bhuvaneshwari et al. 2014). According to the research carried out the strength characteristics of the soil was improved at a significant level so that it can be used as a construction material (Nalbantoğlu 2004; Kate 2005; Mackiewicz and Ferguson 2005; Athanasopoulou 2014; Dhane et al. 2015; Kolay and Ramesh 2016). Apart from experimental work numerical modeling has been addressed by various researchers to understand the stability issues of embankment in terms of factor of safety. In this direction, the optimization of slope angle and their stability issues with the various proportion of fly ash mixed with soil are also addressed by various authors (Martin et al. 1991; Pradhan et al. 2014; Rajak et al. 2017, 2018, 2019; Turkane and Chouksey 2021). 
In soil stabilization, it is important to know the type of stabilizer and its effective use, optimum proportion requires for the stabilization, and methodology adopted for the stabilization process. The robust solutions to address some of the problems can be sorted out through the application of optimization techniques (Sen and Swaminathan 1997; Olgun 2013; Dewangan et al. 2016; Güllü and Fedakar 2017). In a conventional approach, the appropriate proportions of various parameters (fly ash content, slope angle, the height of embankment in the present study) are varied independently. The drawback of the above traditional approach was a time-consuming and uneconomical process to perform large numbers of trials. To address the above issues optimization techniques will be the handy approach. Therefore in this study response surface method (RSM) using second-order models based on FCCCD (faced-centered central composite design) are mostly in practice for the best fit of the experimental data (Güllü and Fedakar 2017). The RSM shows the relationships between independent variables and dependent (response) variables. The main concept of the RSM is to perform a series of experiments to predict the response (Bera and Ghosh 2011; Güllü and Fedakar 2017; Behera et al. 2018; Sharma and Singh 2018).

The objective of this paper is to investigate the fly ash suitability as a sustainable material for geotechnical construction material such as embankment, pavements construction, filling material, and other geotechnical engineering applications. As a result, an increase in fly ash utilization would lead to a lower rate of disposal, optimum use of landfill land, and traditional or base material such as soils (moorum) can be replaced. The results of the above approach would lead to a cost-effective and envirofriendly solution.

\section{Materials \& Sample Preparation}

This paper presents a laboratory investigation of moorum, fly ash, and moorum fly ash mixes at the various proportion of fly ash.

\subsection{Moorum}

The locally available moorum was collected from the NIT Raipur Chhattisgarh, India campus (from $1.2 \mathrm{~m}$ depth below ground surface) for laboratory investigation. The collected moorum sample preliminary dried for 2 days and with help of wooden hammer moorum particles separated. Table 1. presents the geotechnical properties of moorum. 
Table 1

Geotechnical properties of moorum

\begin{tabular}{|lll|}
\hline Sr. No. & Properties & Value \\
\hline 1. & Color & Dark Brown \\
\hline 2. & G (Specific Gravity) & 2.72 \\
\hline 3. & LL (liquid limit \%) & 26.56 \\
\hline 4. & PL (plastic limit \%) & 19.5 \\
\hline 5. & Type of soil as per Indian Standard code & SW \\
\hline 6. & MDD (Maximum Dry Density kN/m ${ }^{3}$ ) & 23.7 \\
\hline 7. & OMC (Optimum Moisture Content \%) & 5.9 \\
\hline
\end{tabular}

\subsection{Fly ash}

The fly ash sample was collected from NSPCL (NTPC-SAIL Power Company Limited), Bhilai, Chhattisgarh, India. Table 2 presents the mechanical properties of fly ash.

Table 2

Mechanical properties of fly ash

\begin{tabular}{|lll|}
\hline Sr. No. & Properties & Value \\
\hline 1. & Color & Dark Gray \\
\hline 2. & Specific Gravity $(\mathrm{G})$ & 2.44 \\
\hline 3. & LL (liquid limit \%) & 34.66 \\
\hline 4. & $\mathrm{PL}($ plastic limit \%) & $\mathrm{NA}$ \\
\hline 5. & $\mathrm{MDD}\left(\mathrm{kN} / \mathrm{m}^{3}\right)$ & 11.7 \\
\hline 6. & $\mathrm{OMC}(\%)$ & 18.9 \\
\hline
\end{tabular}

Table 3 presents the chemical composition of moorum and fly ash based on energy dispersive X-ray (EDX). From the results, the fly ash can be classified as "Class F" according to ASTM C 618 (1996) standard as the sum of $\mathrm{SiO}_{2}, \mathrm{Al}_{2} \mathrm{O}_{3}$, and $\mathrm{Fe}_{2} \mathrm{O}_{3}$ (major oxides) is more than $70 \%$. 
Table 3

Fly Ash and moorum chemical compositions

\begin{tabular}{|llllll|}
\hline Constituents & $\begin{array}{l}\text { Silica \% } \\
\left(\mathrm{SiO}_{2}\right)\end{array}$ & $\begin{array}{l}\text { Alumina \% } \\
\left(\mathrm{Al}_{2} \mathrm{O}_{3}\right)\end{array}$ & $\begin{array}{l}\text { Iron Oxide \% } \\
\left(\mathrm{Fe}_{2} \mathrm{O}_{3}\right)\end{array}$ & $\begin{array}{l}\text { Calcium Oxide } \\
\%(\mathrm{CaO})\end{array}$ & $\begin{array}{l}\text { Magnesium Oxide } \\
\%(\mathrm{MgO})\end{array}$ \\
\hline Fly Ash & 63.78 & 24.44 & 5.01 & 1.94 & 0.48 \\
\hline Moorum & 54.15 & 17.30 & 19.35 & 2.87 & 1.08 \\
\hline
\end{tabular}

\subsection{Moorum-fly ash mixes}

Initially dried moorum sample and fly ash sample is prepared and tested for various laboratory testing. For the moorum fly ash mixes samples the percentage of fly ash varies from 0 to $30 \%(0,15,20,25,30 \%)$ by dry weight of soil. The moorum blended fly ash samples were prepared by mixing the required amount of moorum, fly ash to their respective MDD and OMC. The moorum fly ash mixture samples were prepared by mixing a predetermined proportion of crushed moorum and fly ash in a mixing pan to form a uniform sample for the experimental investigations.

\section{Results And Discussion}

\subsection{The experimental results are presented in the subsequent sections.}

\subsubsection{Atterberg's limit and specific gravity}

The Atterberg's limits of various moorum fly ash mixes were estimated according to the IS: 2720 (Part 5) - 1985. Table 4 presents liquid limit, plastic limit, and specific gravity with various percentages of moorum blended with fly ash. It was observed that the liquid limit of moorum fly ash mixes decreases with the increase in the percentage of fly ash. This is due to the addition of non-plastic material (fly ash) which reduces the water adsorption capacity of mixes.

Table 4

Atterberg's limit and specific gravity

\begin{tabular}{|lllllll|}
\hline Moorum \% & FA \% & LL (\%) & PL (\%) & PI (\%) & IS Soil Class & G \\
\hline 100 & 0 & 26.56 & 19.5 & 7.06 & CL-ML & 2.72 \\
\hline 85 & 15 & 25.49 & - & - & - & 2.67 \\
\hline 80 & 20 & 23.08 & - & - & - & 2.59 \\
\hline 75 & 25 & 22.93 & - & - & - & 2.53 \\
\hline 70 & 30 & 22.16 & - & - & - & 2.46 \\
\hline
\end{tabular}


The plastic limit of moorum is $19.5 \%$ as the replacement of moorum with fly ash the mixes become nonplastic. This can be attributed due to the addition of a percentage of silt particles (as shown in Fig. 1) with increase in the proportion of fly ash, as a result, the mixes become non-plastic.

As per IS: 2720 (Part 3) - 1980 the specific gravity of various mixes were estimated. It was observed that with the replacement of the moorum with fly ash specific gravity of mixes reduces for all the proportions. This may be due to the combination of various factors such as particle size, particle shape, chemical composition. The reduction of specific gravity is mainly due to the presence of a hollow cenosphere (Pandian 2004) which consists of air entrapped particles that cannot be removed. This air entrapped particle increases the volume of fly ash. Also due to the variation in chemical composition especially iron content. The specific gravity plays a vital role in the density of moorum, as the lower the specific gravity lesser the density of moorum as discus in Sect. 3.1.3.

\subsubsection{Grain Size Distribution}

The sieve analysis test was performed according to IS 2720 (Part 4)-1985 for the particle size distribution. The grain size distribution curves for a various proportion of moorum fly ash mixes is shown in Fig. 2. Table 5 presents a variation of silt, clay, and sand fraction contents with the various proportion of fly ash. The moorum shows well-graded (Fig. 1) as the coefficient of uniformity $\left(C_{u}\right)$ is greater than 6 as shown in Table 5 therefore, moorum can classify as well-graded sand (SW) as per IS Code. It has to be noted that with an increase in fly ash content silt and clay fraction increase and sand particles decrease which indicates that the blend forms various ranges of particles.

Table 5

Properties of the grain size distribution

\begin{tabular}{|llllll|}
\hline Moorum \% & FA $\%$ & Silt \& Clay \% & Sand \% & Cu & IS Classification \\
\hline 100 & 0 & 2.37 & 87.33 & 10 & Well-graded sand (SW) \\
\hline 85 & 15 & 12.00 & 78.45 & 30 & Well-graded sand (SW) \\
\hline 80 & 20 & 15.55 & 78.00 & 25.86 & Well-graded sand (SW) \\
\hline 75 & 25 & 17.95 & 73.70 & 21.82 & Well-graded sand (SW) \\
\hline 70 & 30 & 21.15 & 72.45 & 20.37 & Well-graded sand (SW) \\
\hline
\end{tabular}

\subsubsection{Compaction characteristics}

Compaction tests were carried out using a heavy compaction test according to IS 2720 (Part 8) 1983. Figure 3 presents the dry density versus water content for the various proportion of fly ash mixes. The behavior of fly ash is less sensitive with variation in water content than the soils which could explain higher air void content than the soil. Normally, soils have 1 to $5 \%$ of air voids content at maximum dry density, whereas fly ash contains 5 to $15 \%$ (Pandian 2004). From the laboratory results, it was observed 
that the reduction in the maximum dry density (MDD) and increasing optimum moisture content (OMC) with the addition of fly ash is shown in Table 6. Generally, MDD is influenced by the two major factors i.e. specific gravity and particle size distribution. The fly ash particles are finer than moorum particles that easily occupy a large space of moorum. As the proportion of fly ash increases, it acquires a large area and has a low specific gravity, thus a reduction of MDD was attributed. The MDD continuously decreasing with the replacement of moorum by fly ash. As per IRC 36-2010, the maximum dry density requirement for embankment height more than $3 \mathrm{~m}$ should not be less than $16.0 \mathrm{kN} / \mathrm{m}^{3}$. Thus, with the replacement of $30 \%$ fly ash, with the $20.7 \mathrm{kN} / \mathrm{m} 3$ of MDD.

Table 6

Compaction characteristics

\begin{tabular}{|llll|}
\hline Moorum \% & FA \% & OMC\% & MDD kN/m \\
\hline 100 & 0 & 5.9 & 23.7 \\
\hline 85 & 15 & 9.1 & 22.6 \\
\hline 80 & 20 & 8 & 22.45 \\
75 & 25 & 10.5 & 21.2 \\
\hline 70 & 30 & 11.1 & 20.7 \\
\hline
\end{tabular}

\subsubsection{California Bearing Ratio (CBR)}

In the construction of pavement, fly ash is majorly used as a sub-base material. The CBR method is widely used for pavement design. The CBR values of different moorum- fly ash mixes were determined according to IS 2720 (Part 16)1987. The CBR samples were prepared for unsoaked conditions to their given heavy compaction MDD and OMC and further, their respective values were calculated.

Figure 4 shows CBR values under unsoaked conditions for the various proportion of fly ash mixes. It was observed that the CBR value of moorum (62.21\%) is higher for all the proportion of fly ash contents. This mainly due to moorum consists well gradation (all sizes particle) which gives better packing when placed at $95 \%$ of MDD and corresponding OMC, which gives friction-resistant against plunger penetration and exhibits higher capillary force compared to the other proportion of fly ash mixes. From Table 5 (grain size distribution) it was noted that slit and clay fraction increase with the increase in fly ash content as a result water holding capacity of mixes increase which imparts less resistance against penetration as a result lower values of CBR obtained. When optimum moisture is added a thin layer of a film formed around the silt and clay particles that makes soil softer. The water film thinness plays an important role as a lubricant, as the thickness of the film increases frictional resistance decreases (Liu et al. 2009). 


\subsubsection{Direct Shear Test (DST)}

The DST was conducted on moorum- fly ash mixes specimen according to IS 2720 (Part. XIII) 1986, the moorum fly ash mixes specimens were prepared and tested at their respective heavy compaction MDD and $\mathrm{OMC}$ to evaluate the shear strength parameters (cohesion and internal friction $\phi)$. Table 7. presents shear strength parameters of the different proportions of fly ash contents. It has been observed that friction angle decreases and cohesion increase with the increase in the percentage of fly ash contents in mixes. The reduction in friction angle is due to a reduction in sand fraction as it was observed from particle size distribution curves for all the proportions of fly ash mixes as a result sand fraction decreases frictional resistance decrease. On the other hand, with an increase in the percentage of fly ash cohesive property of fly ash mixes increase due to an increase in silt and clay fraction as mentioned in Table 5 . As a result, the water adsorption property of mixes increases The increase in cohesion may due to an increase in cementing and hardening properties of the fly ash at existing optimum moisture (Dewangan et al. 2016).

Table 7

Shear strength parameters of moorum-fly ash mixes

\begin{tabular}{|llll|}
\hline Moorum \% & FA $\%$ & $\phi$ (Degree) & $\mathbf{c}(\mathrm{kPa})$ \\
\hline 100 & 0 & 30.96 & 5 \\
85 & 15 & 25.85 & 19 \\
80 & 20 & 24.10 & 22 \\
75 & 25 & 23.80 & 23 \\
70 & 30 & 23.00 & 25 \\
\hline
\end{tabular}

Based on the above laboratory results it has been seen that moorum can be partially replaced with fly ash to get the desired property as per IS code. The application of moorum fly ash composites is presented in the form of numerical analysis (FLAC/SLOPE version 8.10) for slope stability of the embankment. The subsequent section presents numerical modeling of an embankment with a various proportion of fly ash mixes, a various slope angles, and the height of the embankment.

\subsection{Numerical Modeling}

The slope stability analysis of the moorum embankment and moorum-fly ash mixes embankment was performed using the latest version of FLAC/SLOPE version 8.10. It provides insight for stability analysis in a short time and also describes information regarding critical zones where more precaution is required for short-term and long-term operation of structures. In the present study the stability analysis of moorum-fly ash embankment was carried out at various fly ash (FA) proportions, under different slope angles $(\beta)$ of $30^{\circ}, 32^{\circ}$, and $34^{\circ}$, and at different heights of the embankment $(\mathrm{H}) 6 \mathrm{~m}, 8 \mathrm{~m}$, and $10 \mathrm{~m}$. 
Table 8

FOS for under different geometry

\begin{tabular}{|c|c|c|c|c|}
\hline \multicolumn{2}{|c|}{ Slope Angle } & \multirow{2}{*}{$\begin{array}{l}30^{\circ} \\
\text { FOS }\end{array}$} & \multirow{2}{*}{$\begin{array}{l}32^{\circ} \\
\text { FOS }\end{array}$} & \multirow{2}{*}{$\begin{array}{l}34^{\circ} \\
\text { FOS }\end{array}$} \\
\hline Sample & Height $(m)$ & & & \\
\hline \multirow[t]{3}{*}{ FAO } & 6 & 1.53 & 1.44 & 1.36 \\
\hline & 8 & 1.43 & 1.34 & 1.24 \\
\hline & 10 & 1.36 & 1.27 & 1.19 \\
\hline \multirow[t]{3}{*}{ FA15 } & 6 & 2.22 & 2.12 & 2.04 \\
\hline & 8 & 1.94 & 1.86 & 1.78 \\
\hline & 10 & 1.78 & 1.70 & 1.62 \\
\hline \multirow[t]{3}{*}{ FA20 } & 6 & 2.3 & 2.21 & 2.13 \\
\hline & 8 & 1.99 & 1.91 & 1.83 \\
\hline & 10 & 1.81 & 1.72 & 1.65 \\
\hline \multirow[t]{3}{*}{ FA25 } & 6 & 2.41 & 2.32 & 2.24 \\
\hline & 8 & 2.08 & 1.99 & 1.91 \\
\hline & 10 & 1.87 & 1.79 & 1.72 \\
\hline \multirow[t]{3}{*}{ FA30 } & 6 & 2.52 & 2.41 & 2.34 \\
\hline & 8 & 2.15 & 2.06 & 1.98 \\
\hline & 10 & 1.92 & 1.84 & 1.77 \\
\hline
\end{tabular}

Table 8 presents a variation of FOS under different slope angles and heights for the various proportion of moorum fly-ash mixed. It is observed that the moorum embankment without fly ash was stable up to $8 \mathrm{~m}$ and $6 \mathrm{~m}$ height at $30^{\circ}$ and $32^{\circ}$ slope angle respectively, with a limiting value of FOS of 1.4 at the end of construction (as per IRC 75: 2015). However, with the replacement of fly ash up to $30 \%$, the FOS of all the samples increases for all the heights, and for a given proportion the FOS decreases with an increase in height. For example, in the case of $30 \%$ fly ash and slope angle of $30^{\circ}$ for height $6 \mathrm{~m}$ FOS is 2.52 whereas, FOS reduced to 1.92 for the height of $10 \mathrm{~m}$. It is due to a decrease in the shear stress of soil mixes. This reduction in shear stress is attributed due to an increase in fly ash content which is more uniform in shape (spherical) and having less resistance against shear. It was also observed that with increase in slope angles FOS decrease as result slopes are becoming steeper. 
The interpretation of the above results is verified based on the analytical approach. Non-linear equations are derived for estimation of FOS with consideration of variable parameters such as fly ash content (FA), slope angle $(\beta)$, and height of embankment $(H)$. The equations are derived from response surface methodology (RSM) based face-centered central composite design (FCCCD) for the prediction of FOS. The statistical tool analysis of variance (ANOVA) is used for a better understanding of the influence of various variable parameters on the predicted response.

\section{Response Surface Method (Rsm)}

Response surface methodology (RSM) is a set of mathematical and statistical methods that are a beneficial technique for improving, developing, and optimizing processes. RSM's most wide applications in the industrial world, especially in situations where lots of input data variables potentially affect performance or quality characteristics of the product or process. These performance measures or quality characteristics are referred to as response. The input variables are called independent variables, and they are subject to the regulate the engineer or scientist, at least for purposes of a test or an experiment (Myers et al. 2016; Güllü and Fedakar 2017).

\subsection{Model Development}

The model is developed using the input factors in terms of the amount of fly ash content (FA) varying from $0-30 \%$, heights of the embankment $(H)$ from $6 \mathrm{~m}$ to $10 \mathrm{~m}$, slope angles $(\beta)$ from $30^{\circ}$ to $34^{\circ}$ respectively. Table 9 shows the experimental levels of input factors. The levels in form of "minimum", "mean", and "maximum" are "-1", "0", \& "1" real values of input factors, respectively.

Table 9

Experimental Level

\begin{tabular}{|llll|}
\hline Variable & \multicolumn{3}{l}{ Level } \\
\cline { 2 - 4 } & $\mathbf{- 1}$ & $\mathbf{0}$ & $\mathbf{1}$ \\
\hline Fly Ash (FA\%) & 0 & 15 & 30 \\
\hline Slope Angle $\left(\beta^{0}\right)$ & 30 & 32 & 34 \\
\hline Height $(\mathrm{H} \mathrm{m})$ & 6 & 8 & 10 \\
\hline
\end{tabular}

In this paper, the experiment was designed using 'Face-centered central composite design' (FCCCD) to develop the response surface model. It contains six axial points, eight factorial points, and six center points. The information related to existing curvature and pure error inbuilt system was given by a centered point, where the axial points permit the estimation of quadratic terms in the model (Myers et al. 2016). Experimental design (RSM predicted) and numerically (FLAC/SLOPE version 8.10) observed FOS were presented in Table 10. The full quadratic model was performed with a confidence level of $95 \%$ to 
build the RSM model. For the design of experiments and RSM model development with ANOVA analysis, Design Experts (by Stat-Ease, Inc) a trial version of the software package, has been used.

Table 10

FCCCD Experiments and FOS results

\begin{tabular}{|c|c|c|c|c|c|c|c|}
\hline \multicolumn{3}{|c|}{ Experimental design } & \multicolumn{2}{|c|}{ Experimental test } & \multicolumn{2}{|r|}{ FOS } & \multirow{3}{*}{ ANOVA } \\
\hline FA & $\beta$ & $\mathrm{H}$ & FA & $\beta$ (Degree) & $\mathrm{H}$ & Numerically observed & \\
\hline & & & $(\%)$ & & (m) & & \\
\hline-1 & -1 & -1 & 0 & 30 & 6 & 1.55 & 1.56 \\
\hline 1 & -1 & -1 & 30 & 30 & 6 & 2.52 & 2.52 \\
\hline-1 & 1 & -1 & 0 & 34 & 6 & 1.36 & 1.37 \\
\hline 1 & 1 & -1 & 30 & 34 & 6 & 2.32 & 2.32 \\
\hline-1 & -1 & 1 & 0 & 30 & 10 & 1.36 & 1.35 \\
\hline 1 & -1 & 1 & 30 & 30 & 10 & 1.92 & 1.91 \\
\hline-1 & 1 & 1 & 0 & 34 & 10 & 1.19 & 1.19 \\
\hline 1 & 1 & 1 & 30 & 34 & 10 & 1.76 & 1.75 \\
\hline-1 & 0 & 0 & 0 & 32 & 8 & 1.34 & 1.32 \\
\hline 1 & 0 & 0 & 30 & 32 & 8 & 2.06 & 2.08 \\
\hline 0 & -1 & 0 & 15 & 30 & 8 & 1.94 & 1.95 \\
\hline 0 & 1 & 0 & 15 & 34 & 8 & 1.78 & 1.77 \\
\hline 0 & 0 & -1 & 15 & 32 & 6 & 2.13 & 2.10 \\
\hline 0 & 0 & 1 & 15 & 32 & 10 & 1.70 & 1.71 \\
\hline 0 & 0 & 0 & 15 & 32 & 8 & 1.86 & 1.86 \\
\hline 0 & 0 & 0 & 15 & 32 & 8 & 1.86 & 1.86 \\
\hline 0 & 0 & 0 & 15 & 32 & 8 & 1.86 & 1.86 \\
\hline 0 & 0 & 0 & 15 & 32 & 8 & 1.86 & 1.86 \\
\hline 0 & 0 & 0 & 15 & 32 & 8 & 1.86 & 1.86 \\
\hline 0 & 0 & 0 & 15 & 32 & 8 & 1.86 & 1.86 \\
\hline
\end{tabular}


The experimental data were examined at a 95\% confidence level to express the empirical model using RSM for the parameters (FA, $\beta$, and $H$ ) on the response variable (FOS) using a non-linear equation was used. The ANOVA was performed to understand the effect of each parameter and their contribution towards response prediction. The ANOVA gives the results of added terms $(p \leq 0.05)$ that are less than 0.05 which shows that the built model is statically significant. The statistically insignificant terms $(p>$ 0.05) are removed by the backward analysis on a full quadratic model. Table 11. presents the sum of squares values (SS), mean square (MS), degree of freedom (df), F-value, p-value. The sum of squares calculated by the addition of the sum of regression for individual parameters and a sum of residual random errors. The mean square is evaluated by dividing the corresponding sum of regression and residual errors by the degree of freedom. The F-value is evaluated by the ratio of the mean square of regression to mean square of errors and which was compared with Fisher distribution (Pradhan and Bhattacharjee 2009; Olgun 2013; Güllü and Fedakar 2017). The percentage contribution of build model parameters on the performance of FOS is estimated from the F-values. The F-value of each parameter is divided by the sum of F-values multiply by 100 . Figure 8 presents the percentage contribution of built model parameters. It was observed that fly ash content has a significant effect on the performance of FOS as compare to slope angle and height. This may be due to the low unit weight of moorum fly ash mixes which affects the performance of FOS. However, from the analysis, only the interaction term (i.e., FA*H) has a significant contribution to FOS. 
Table 11

Result of ANOVA for the RSM model

\begin{tabular}{|llllll|}
\hline Source & SS & df & MS & F-value & p-value \\
\hline Model & 2.06 & 6 & 0.3432 & 1802.65 & $<0.0001$ \\
\hline A-FA & 1.43 & 1 & 1.43 & 7505.02 & $<0.0001$ \\
\hline B-SA & 0.0774 & 1 & 0.0774 & 406.76 & $<0.0001$ \\
\hline C-H & 0.3803 & 1 & 0.3803 & 1997.27 & $<0.0001$ \\
\hline AC & 0.0800 & 1 & 0.0800 & 420.20 & $<0.0001$ \\
\hline A $^{2}$ & 0.0806 & 1 & 0.0806 & 423.59 & $<0.0001$ \\
\hline C $^{2}$ & 0.0068 & 1 & 0.0068 & 35.95 & $<0.0001$ \\
\hline Residual & 0.0025 & 13 & 0.0002 & & \\
\hline Lack of Fit & 0.0025 & 8 & 0.0003 & & \\
\hline Pure Error & 0.0000 & 5 & 0.0000 & & \\
\hline Cor Total & 2.06 & 19 & & & \\
\hline $\mathrm{R}^{2}$ & 0.9988 & & Predicted R & 0.9959 & \\
\hline Adjusted $\mathrm{R}^{2}$ & 0.9982 & & Adeq Precision & 161.9502 & \\
\hline
\end{tabular}

From Table 11, the determination coefficient $\left(R^{2}\right)$ of the developed model was found to be 0.9988 , nearly equal to 1 . This indicates that variation of response is strongly fitted by the input factors. The higher $\mathrm{R}^{2}$ does not indicate that the regression model is the best fit one. With the addition of variables to the model, $\mathrm{R}^{2}$ always increases, irrespective of whether the additional parameters are statistically significant or not. Therefore, the regression model significances can be checked using the adjusted $R^{2}$. As Adj $R^{2}$ statistic will omit the unnecessary added terms which decreases Adj $R^{2}$ (Myers et al. 2016). As the Adj $R^{2}$ is found to be 0.9982 which is less than the $\mathrm{R}^{2}$ indicating predicted FOS and observed FOS has strong harmony with each other. The Predicted $\mathrm{R}^{2}$ gives some hint of the predictive ability of the regression model (Myers et al. 2016). Here, Predicted $R^{2}$ (Pred $R^{2}$ ) is 0.9959 i.e. this model explains that $99.59 \%$ of the variability of predicting new data as compared to $99.88 \%$ of the variability in the actual data noted by the leastsquares fit. The Pred $R^{2}$ of 0.9959 is in reasonable agreement with the Adj $R^{2}$ of 0.9982 ; i.e. the difference is less than 0.2. Adequate Precision (AP) measures the ratio of signal to noise. A ratio that should be greater than 4 is required (Myers et al. 2016). This model shows an adequate signal as the ratio is 161.9502. From the statistical value of $R^{2}$, Pred $R^{2}, A P$, and $A d j R^{2}$, it can be summarized that the developed RSM model is the best suit.

The RSM model formulates the mathematical relationship of the experimental design to predict the response (FOS) as established in Eq. (1). The terms in the equation are in the form of natural variables 
that can be used to make the predictions about the response for given levels as mention in Table 10 .

FOS $=3.851+0.073033$ FA $-0.044 \beta-0.2325 \mathrm{H}-0.0033 F A^{*} \mathrm{H}-0.000706 \mathrm{FA}^{2}+0.011562 \mathrm{H}^{2}(1)$

\subsection{Adequacy of model}

The adequacy of the developed model was checked by calculating the values of $R^{2}$, Adj $R^{2}, A P$, and Pred $\mathrm{R}^{2}$. Also, it can be checked by residual analysis from least-square fit which is based on two assumptions

i) Normality and ii) equal variance. The normal assumption check can be made by plotting normal probability versus residuals. If the residuals plot approximately along a straight line, then the normality assumption is satisfied (Myers et al. 2016). It is mandatory to examine that the developed model gives an approximate adequate result to the true system, and to ensure that whether any of the least-squares regression assumptions are violated. (Myers et al. 2016; Güllü and Fedakar 2017). Thus, in this paper, the adequacy of the model is examined with help of a plot of residuals versus normal probability (\%) and by calculating the determination coefficient $\left(R^{2}\right)$, predicted $R^{2}$ (Pred $R^{2}$ ), adjusted $R^{2}\left(\operatorname{Adj} R^{2}\right)$, values. Figure 9 presents a normal probability plot versus internally studentized residuals shows that almost all the points that fall on the straight line indicate the adequacy of the developed RSM model.

For equal variance assumption, the original observations of variance were constant for all values of measured response. Generally, this assumption is used to suggest the requirement of the alteration of the response variable (Myers et al. 2016). So, it can be checked by plotting the internally studentized residuals versus predicted response. Figure 10 shows that with internally studentized residuals response is constant which implies that model adequacy.

\section{Conclusions}

In this paper, laboratory experiments were performed to examine the maximum utilization of fly ash and stability analysis of moorum-fly ash in an embankment. Also, face-centered central composite design by response surface methodology (RSM) approach was used to derive a non-linear equation for the variable input parameters of FA, SA, and height of embankment and output as a FOS. Based on experiments, numerical simulation, and analytical approach following conclusions are drawn:

1. Atterberg's limit of moorum fly ash mixes changes to non-plastic from plastic state with the replacement of fly ash content. The specific gravity of the moorum fly ash mixes reduces with an increment of fly ash content due to the lightweight of fly ash.

2. As fly ash content increases in moorum-fly ash mixes, the reduction in maximum dry density and increasing optimum moisture content.

3. The CBR value for the moorum fly ash mixes reduces with increasing the percentage of fly ash.

4. The cohesion of moorum-fly ash mixes increases with an increase in fly ash content whereas the angle of internal friction decreases due to cementation and hardening property of fly ash.

5. Based on numerical simulation of moorum fly-ash mixes embankment FOS increases with increase in fly ash content whereas FOS decreases with increase in height and slope angle. 
6. The nonlinear equation was developed based on the statistical tool (ANOVA) to show the relationship between a dependent (FOS) and an independent variable (FA, SA, and $\mathrm{H}$ ).

7. The developed mathematical relation gives a reasonably good prediction of FOS as validated with the numerical simulation.

8. Adequacy of the developed model is verified with reference to the $R^{2}$, Adj $R^{2}$, Pred $R^{2}$, and AP. The values of $R^{2}$ are close to 1 and adequate precision is greater than 4 .

9. Adequacy of the model is also represented in terms of normal probability plot vs residual and residual vs. predicted. The plotted points fall along the straight line corresponding to the normal probability plot showing the adequacy of the model and studentized residuals response is constant which implies model adequacy.

\section{Declarations}

Acknowledgements -The authors would like to acknowledge the Ministry of Human Resources and Development (M.H.R.D), India and National Institute of Technology Raipur, India for all help and support.

\section{Compliance with ethical standards}

Conflict of interest- The authors declare that they have no confict of interest

\section{References}

Athanasopoulou A (2014) Addition of lime and fly ash to improve highway subgrade soils. J Mater Civ Eng 26:773-775. https://doi.org/10.1061/(ASCE)MT.1943-5533.0000856

Behera SK, Meena H, Chakraborty S, Meikap BC (2018) Application of response surface methodology (RSM) for optimization of leaching parameters for ash reduction from low-grade coal. Int J Min Sci Technol 28:621-629. https://doi.org/10.1016/j.ijmst.2018.04.014

Bera AK, Ghosh A (2011) Regression model for prediction of optimum moisture content and maximum dry unit weight of fine grained soil. Int J Geotech Eng 5:297-305.

https://doi.org/10.3328/IJGE.2011.05.03.297-305

Bhuvaneshwari S, Robinson RG, Gandhi SR (2014) Stabilization of Expansive Soils Using Flyash and Murrum. Int J Innov Res Sci Eng Technol 1-10

Bose B (2012) Geo-engineering properties of expansive soil stabilized with fly ash. Electron J Geotech Eng $17 \mathrm{~J}: 1339-1353$

Central Electricity Authority (2018) Fly Ash Generation at Coal / Lignite Based Thermal Power Stations and its Utilization in the Country. 18:1-32 
Cokca E (2001) Use Class C fly Ashes for the Stabilization of an Expansive Soil. J Geotech Geoenvironmental Eng 127:568-573

Dewangan PK, Pradhan M, Ramtekkar GD (2016) Shear strength behaviour of fly ash mixed coal mine overburden dump material and stability assessment using numerical modelling. ARPN J Eng Appl Sci $11: 615-628$

Dhane G, Kumar D, Priyadarshee A (2015) Effect of fly ash on the properties of black cotton soil: a review. Int J Adv Technol Eng Sci 596-604

Güllü H, Fedakar Hi (2017) Response surface methodology for optimization of stabilizer dosage rates of marginal sand stabilized with Sludge Ash and fiber based on UCS performances. KSCE J Civ Eng 21:1717-1727. https://doi.org/10.1007/s12205-016-0724-x

Kaniraj SR, Gayathri V (2003) Factors influencing the strength of cement fly ash base courses. J Transp Eng 129:538-548. https://doi.org/10.1061/(ASCE)0733-947X(2003)129:5(538)

Kate JM (2005) Strength and volume change behavior of expansive soils treated with fly ash. Geotech Spec Publ c:1851-1865

Kolay PK, Ramesh KC (2016) Reduction of Expansive Index, Swelling and Compression Behavior of Kaolinite and Bentonite Clay with Sand and Class C Fly Ash. Geotech Geol Eng 34:87-101. https://doi.org/10.1007/s10706-015-9930-4

Liu Z, Zhang Y, Di J (2009) Analysis on the factors affecting the CBR value of silt roadbed. Proc 2nd Int Conf Transp Eng ICTE 2009 2009:1814-1819. https://doi.org/10.1061/41039(345)300

Mackiewicz SM, Ferguson EG (2005) Stabilization of Soil with Self-Cementing Coal Ashes. 2005 World Coal Ash (WOCA), April 11-15, 2005, Lexington, Kentucky, USA 1-7

Martin JP, Collins RA, Browning JS, et al (1991) PROPERTIES AND. USE OF FLY ASHES FOR EMBANKMENTS By. J Energy Eng 116:71-86

Myers RH, Montgomery DC, Anderson- cook CM (2016) Response Surface Methodology, Fourth. John Wiley \& Sons, Inc., Hoboken, New Jersey

Nalbantoğlu Z (2004) Effectiveness of class C fly ash as an expansive soil stabilizer. Constr Build Mater 18:377-381. https://doi.org/10.1016/j.conbuildmat.2004.03.011

Olgun M (2013) The effects and optimization of additives for expansive clays under freeze-thaw conditions. Cold Reg Sci Technol 93:36-46. https://doi.org/10.1016/j.coldregions.2013.06.001

Pandian NS (2004) Fly ash characterization with reference to geotechnical applications. J indian institite Sci 84:189-216 
Phani Kumar BR, Sharma RS (2004) Effect of fly ash on engineering properties of expansive soils. J Geotech Geoenvironmental Eng 130:764-767. https://doi.org/10.1061/(ASCE)10900241(2004)130:7(764)

Pradhan B, Bhattacharjee B (2009) Performance evaluation of rebar in chloride contaminated concrete by corrosion rate. Constr Build Mater 23:2346-2356. https://doi.org/10.1016/j.conbuildmat.2008.11.003

Pradhan SP, Vishal V, Singh TN, Singh VK (2014) Optimisation of Dump Slope Geometry Vis-à-vis Flyash Utilisation Using Numerical Simulation. Am J Min Metall 2:1-7. https://doi.org/10.12691/ajmm-2-1-1

Rajak TK, Yadu L, Chouksey SK, Dewangan PK (2018) Stability analysis of mine overburden dump stabilized with fly ash. Int J Geotech Eng 00:1-11. https://doi.org/10.1080/19386362.2018.1503780

Rajak TK, Yadu L, Chouksey SK, Pal SK (2017) Strength Characteristics of Fly Ash Stabilized Soil Embankment and Stability Analysis Using Numerical Modelling. Indian Geotech Conf 2017 GeoNEst 2720:14-17

Rajak TK, Yadu L, Pal SK (2019) Analysis of slope stability of fly ash stabilized soil slope. Springer Nature Singapore

Sen R, Swaminathan T (1997) Application of response-surface methodology to evaluate the optimum environmental conditions for the enhanced production of surfactin. Appl Microbiol Biotechnol 47:358363. https://doi.org/10.1007/s002530050940

Sharma LK, Singh TN (2018) Regression-based models for the prediction of unconfined compressive strength of artificially structured soil. Eng Comput 34:175-186. https://doi.org/10.1007/s00366-0170528-8

Sivapullaiah P V., Prashanath JP, Sridharan A (1996) Effect of Fly ash on the Index Properties of Black Cotton Soil. Soils Found 36:97-103

Turkane SD, Chouksey SK (2021) Partial replacement of moorum with fly ash in embankment. Lect Notes Civ Eng 77:381-391. https://doi.org/10.1007/978-981-15-5195-6_30

\section{Figures}




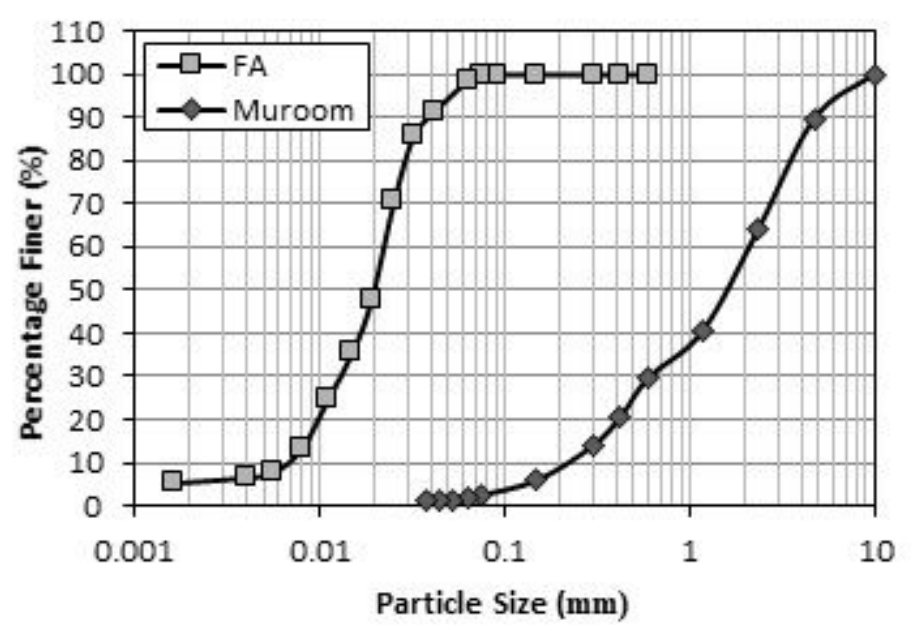

\section{Figure 1}

Grain Size Distribution for moorum and fly ash

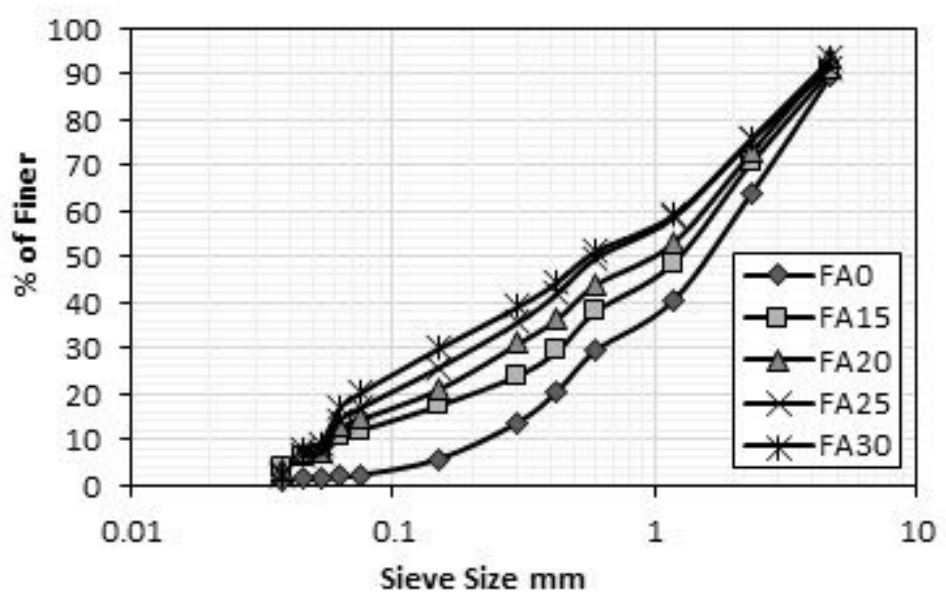

Figure 2

Grain size distribution curve

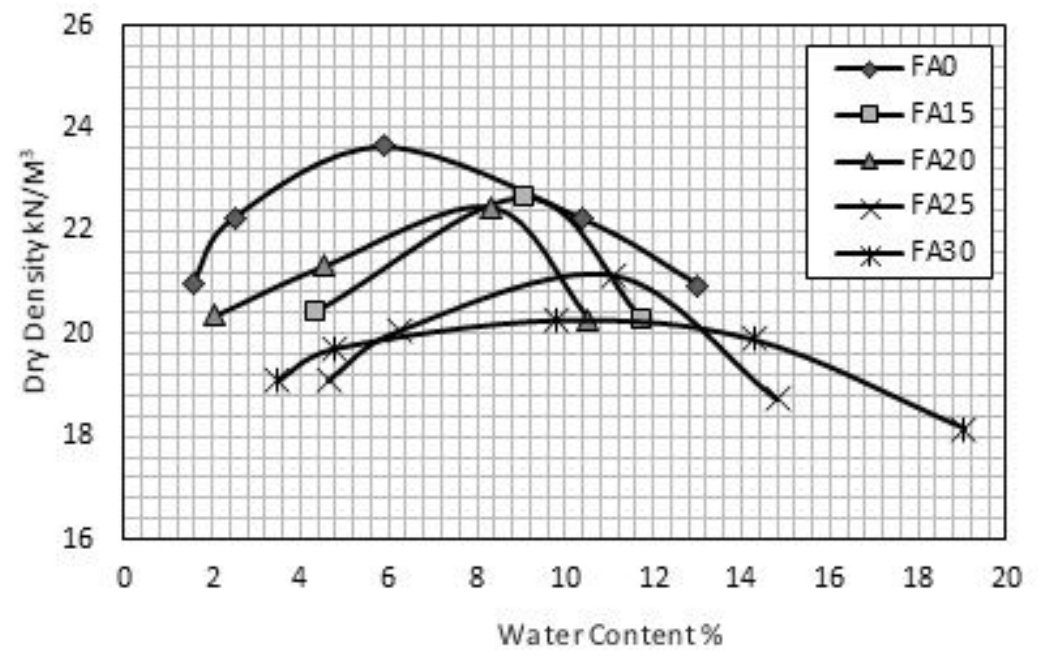

Figure 3 
Compaction curves for moorum fly ash mixes

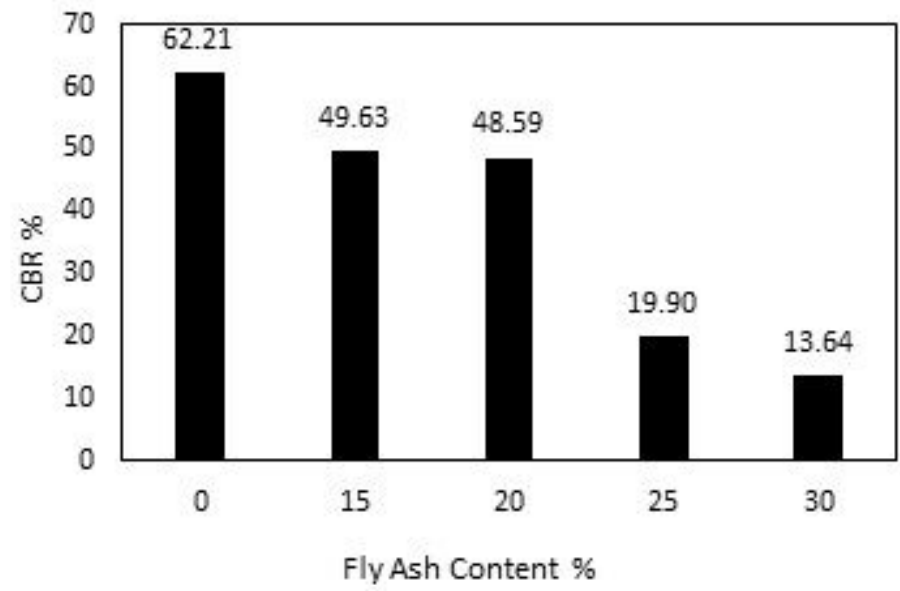

Figure 4

CBR values

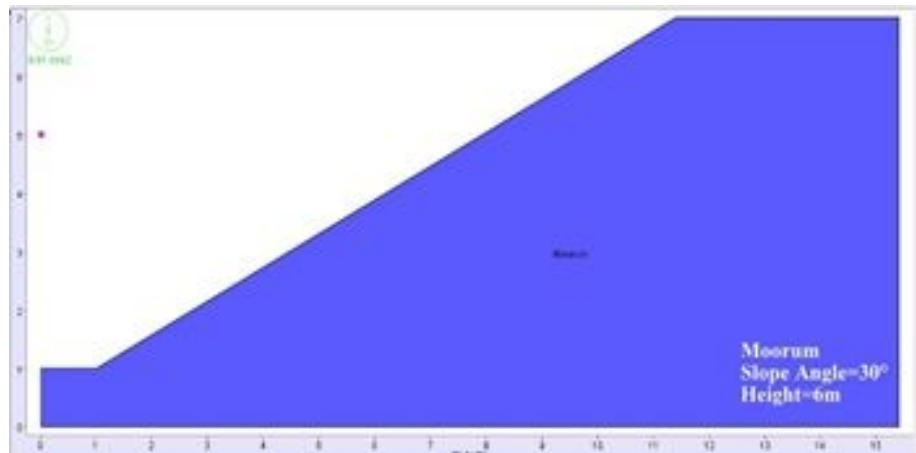

Figure 5

Typical geometry of the Embankment

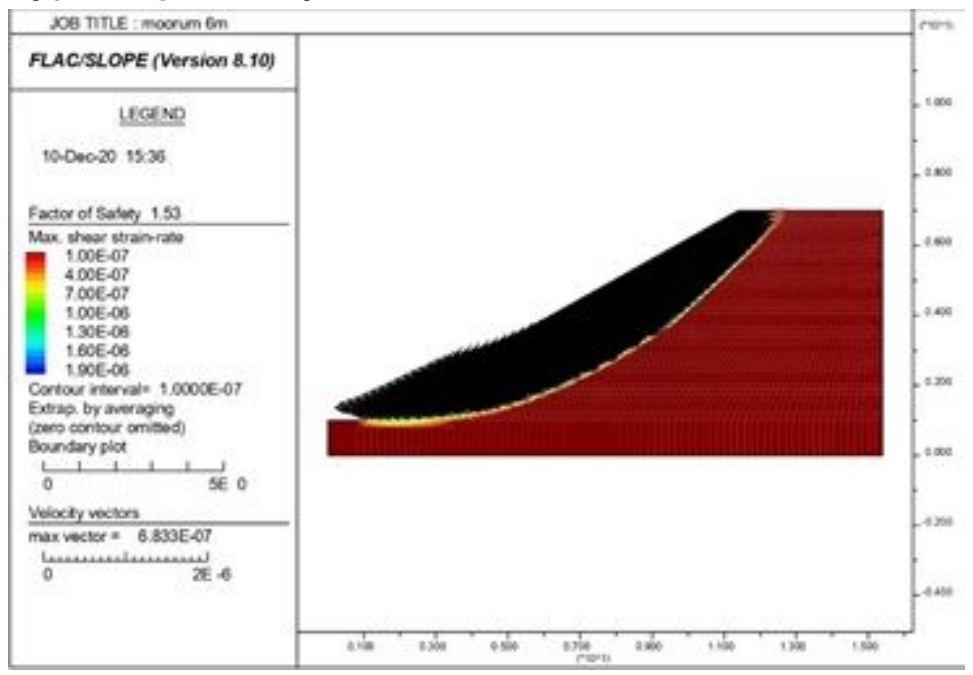

Figure 6

Variation of FOS, SSR, and VV for moorum embankment at 6m height and 300 slope angle 


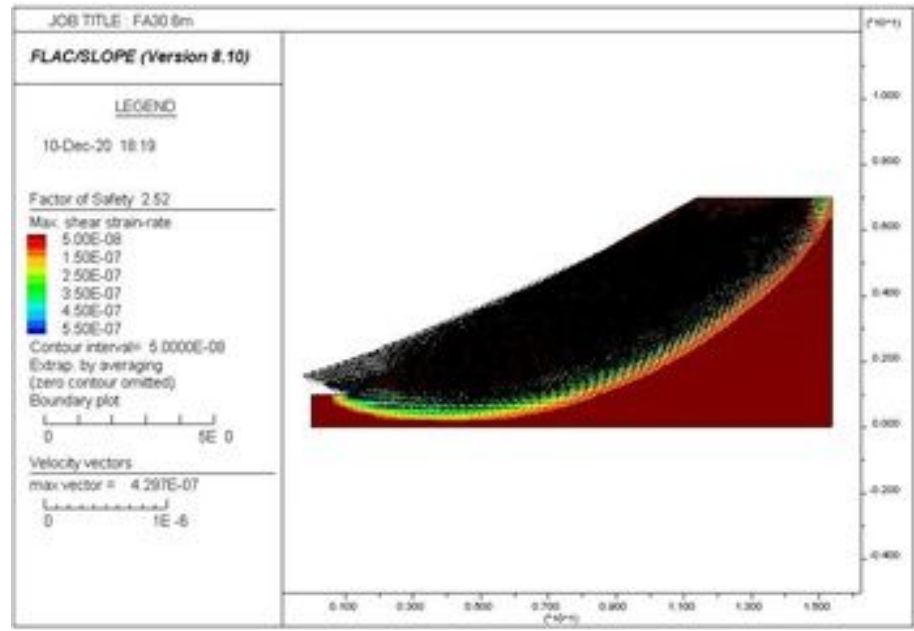

Figure 7

Variation of FOS, SSR, and VV for 30\% fly ash embankment at $6 \mathrm{~m}$ height and 300 slope angle

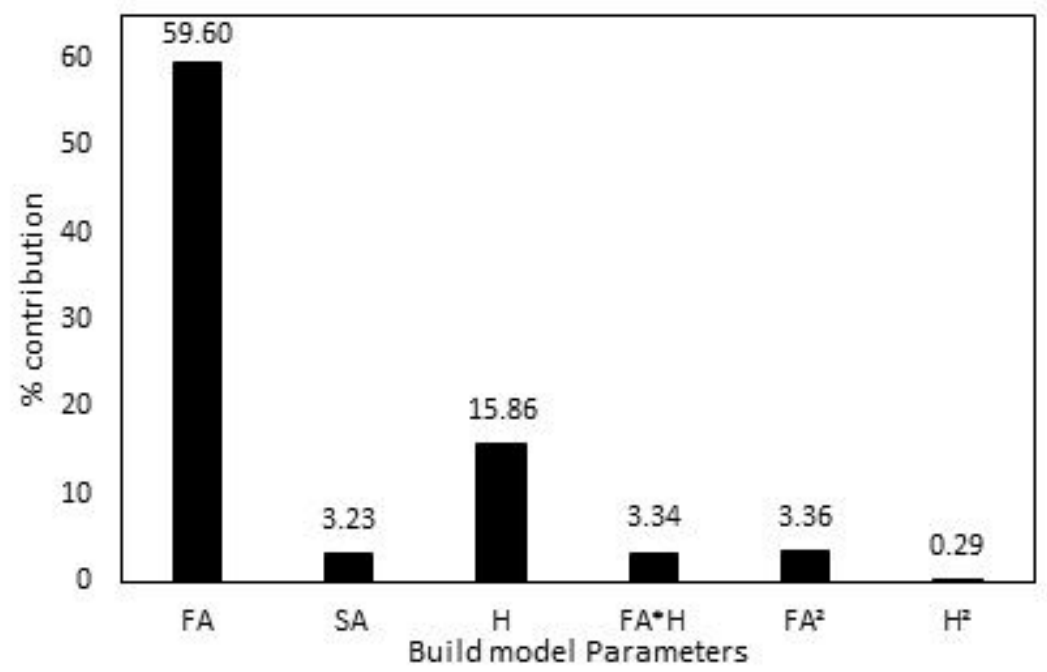

Figure 8

Contribution of built model parameters on FOS results 


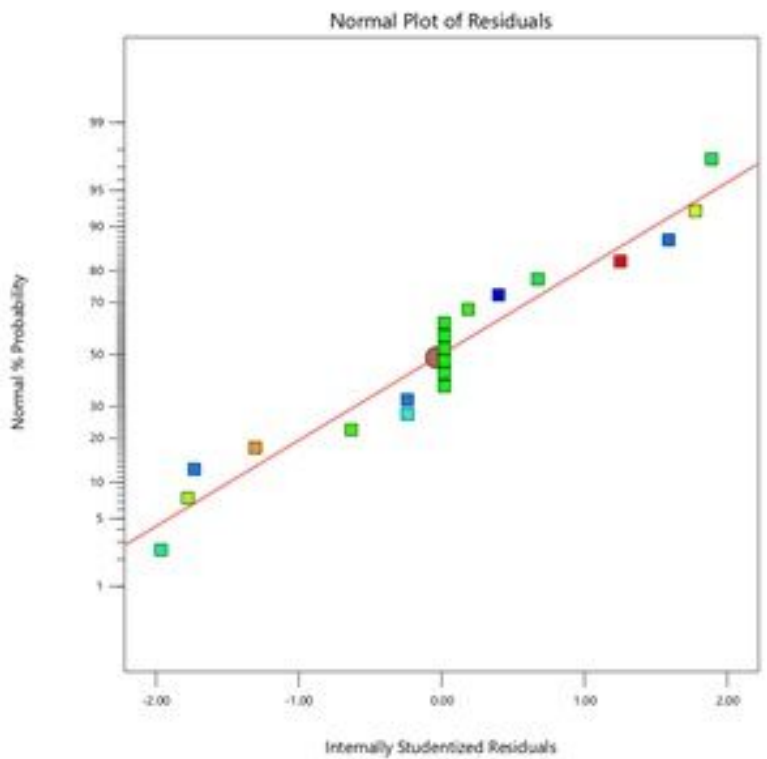

Figure 9

Normal \% probability plot versus internally studentized residuals

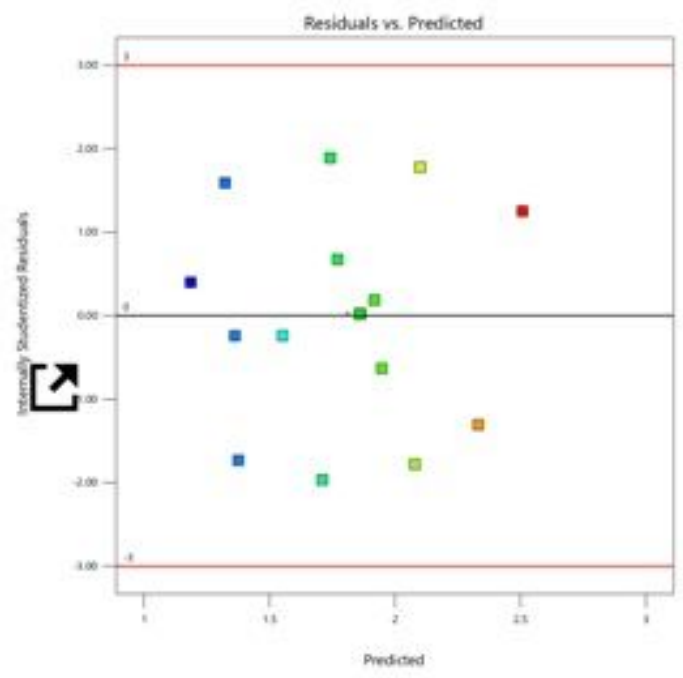

Figure 10

Plot for internally studentized residuals versus predicted response 